\title{
Using Padlet for collaborative learning
}

\section{Inma Beltrán-Martín}

Department of Business Management and Marketing, Universitat Jaume I, Spain.

\begin{abstract}
Technology-based collaborative learning is attaining increasing relevance in higher education. Despite the considerable number of tools and online applications that support collaborative learning, their adoption in classroom courses is still in its early stages. This paper focuses on Padlet and presents some of the uses of this web application that support collaborative learning in classroom teaching. In particular, we summarize the process of collaborative learning through Padlet in the Master's Degree for Secondary Education, Vocational Training and Language Teaching. The uses of Padlet can be summarized in six: research resource gathering, class resources, class diary, FAQ, brainstorming, online dialogue.
\end{abstract}

Keywords: Collaborative learning; Padlet; Multimedia wall. 


\section{Introduction}

Technology-based collaborative learning is attaining increasing relevance in higher education for a number of reasons, such as the prevalence of constructivism as a teaching and learning approach or the need to increase student engagement, among others. Online collaborative learning can be defined as a learning process in which students work together to analyze a question or create shared meaning (Harasim et al., 1995). This is a process characterized by a number of features, such as the active nature of learning, the role of the teacher as a facilitator of students' learning and the increased students' responsibility for their own learning (Kirschner, 2001). Nowadays, there is a significant number of tools and online applications that support collaborative learning (e.g. Google web applications, Edmodo, Facebook, etc.) but their adoption in classroom courses is still in its early stages (Hsu et al., 2014).

This paper focuses on Padlet and presents some of the uses of this web application that support collaborative learning in higher education. In particular, we summarize the process of collaborative learning through Padlet in the Master's Degree for Secondary Education, Vocational Training and Language Teaching at University Jaume I (Spain). One of the primary purposes of this Master's Degree is to shape the idea that teaching is a thoughtful process and that future teachers should introduce reflection in their daily activities (i.e. they should not act based on impulse or intuition) and that they need to interact with other teachers to improve the quality of their teaching. We believe that in this context, collaborative learning may help students to retain information, increase their motivation and improve critical thinking skills (Cavanagh, 2011) all of which are of crucial value for future teachers.

\section{Uses of Padlet for collaborative learning}

According to Resta and Laferrière (2007) there are four instructional motives that justify the use of technology as a way of introducing collaborative learning in the classroom (Figure 1). 


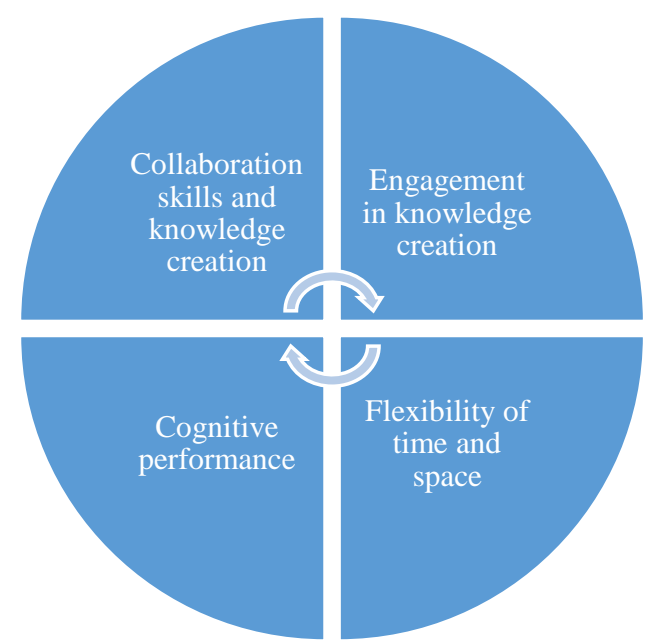

Figure 1. Instructional motives for the use of technology in collaborative learning. Source: own elaboration based on Resta and Laferrière (2007).

First, it helps students to be ready for the knowledge society by increasing their collaboration skills and knowledge creation. Second, it contributes to enhance students' cognitive performance and to promote deep understandings of key concepts. Third, it provides the teaching process with higher flexibility of time and space for collaborative learning and fourth, it promotes students' engagement in knowledge creation. Bearing these motives in mind, we structured the teaching process in the Master's Degree using Padlet.

Padlet (www.padlet.com) is a free multimedia wall that allows real-time interaction both among students and between the students and the teacher and that facilitates whole-class participation (Fuchs, 2014). An increasing number of teachers during recent years has recognized that Padlet is a useful tool to improve collaborative learning. Some of its advantages are: a) easy to use, b) instant collaboration (any student can see when anyone else is uploading something in the wall), c) multimedia (almost everything can be placed on the Padlet) and d) mobile (it can work on many different devices) (Zhi and Su, 2015). Its applications in the classroom are endless, from a tool to evaluate lessons until a way of asking for ideas. In addition, files from the Padlet walls can be saved and copied into any other application. Padlet can be used for simple tasks or for expert teaching and it does not require special training or experience in the use of web 2.0 tools (Weller, 2013). Based on the model summarized in Figure 1, six applications of Padlet were crucial during the teaching process of the Master's Degree, namely research resource gathering, class resources, class diary, FAQ (frequently asked questions), brainstorming and online 
dialogue (Figure 2). In our opinion, these applications contribute to the four instructional motives that we described above.

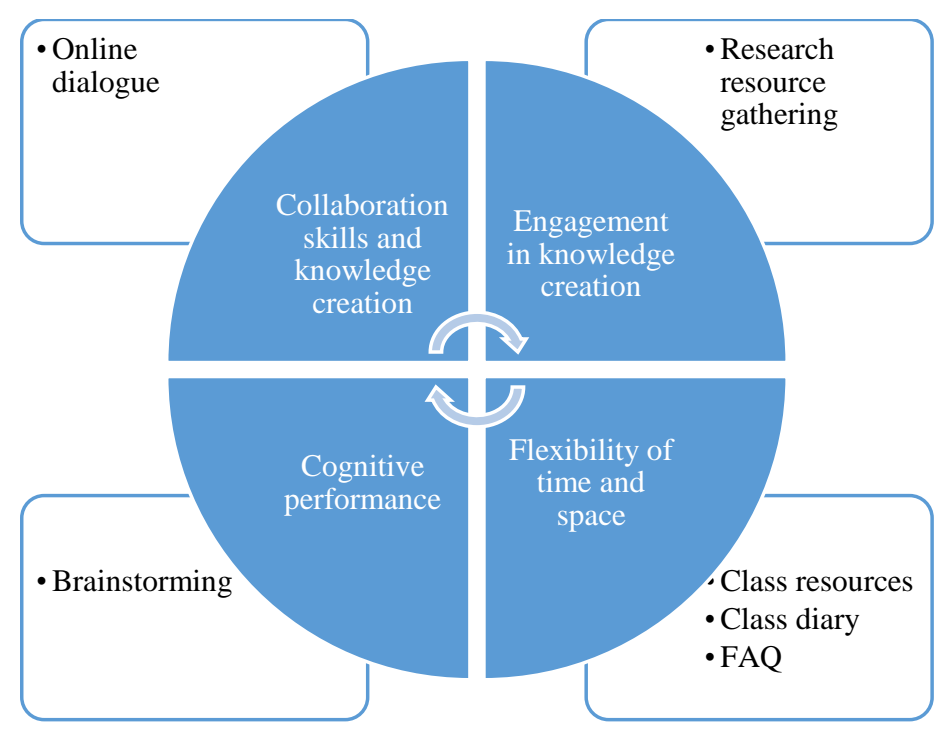

Figure 2. Uses of Padlet. Source: own elaboration.

\subsection{Research resource gathering}

Students in the Master's Degree for Secondary Education, Vocational Training and Language Teaching should be familiar with innovative teaching techniques. One of the aims of our course is to motivate students to introduce innovative teaching and learning procedures as a way of increasing the engagement of their future students in the secondary and vocational schools. Innovation skills should be present in secondary teachers but innovation requires, as a first step, to know and understand innovative methodologies. Therefore, it is essential that our students in the Master's Degree assimilate the wide array of innovative teaching methods that can be used in the classroom, together with their advantages and disadvantages. For this reason, we asked our students in the Master's Degree to create an Innovative Teaching Padlet to hold ideas, sources and descriptions of several innovative teaching methodologies. This Padlet constitutes the virtual book of our course and has been created through the collaboration of all the students. In addition, Padlet forces students to summarize ideas and write something concise, which also contributes to their learning. The content and structure of the Innovative Teaching Padlet varies from year to year, depending on the interests and motivations of the students (Figure 3). 


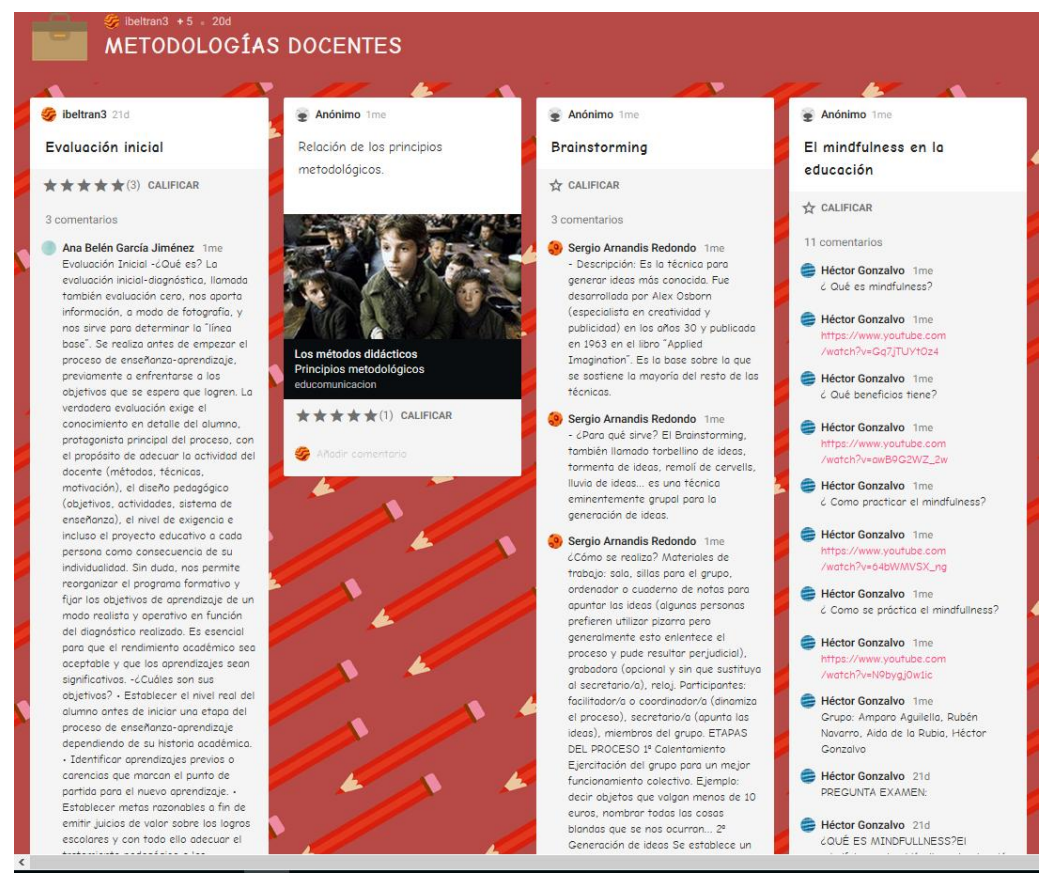

Figure 3. The Innovative Teaching Padlet

\subsection{Class resources}

Any type of file can be posted on Padlet and it can be viewed instantly on the wall so it provides a valuable way to compile teaching resources. In doing so, we created as many Padlets as classroom sessions we had with the students and we inserted hyperlinks in the corresponding calendar (Figure 4). Then, the teacher and the students placed the videos, documents and images that were used during the lessons in the corresponding Padlet. The students could read and download the resources directly from the wall. 


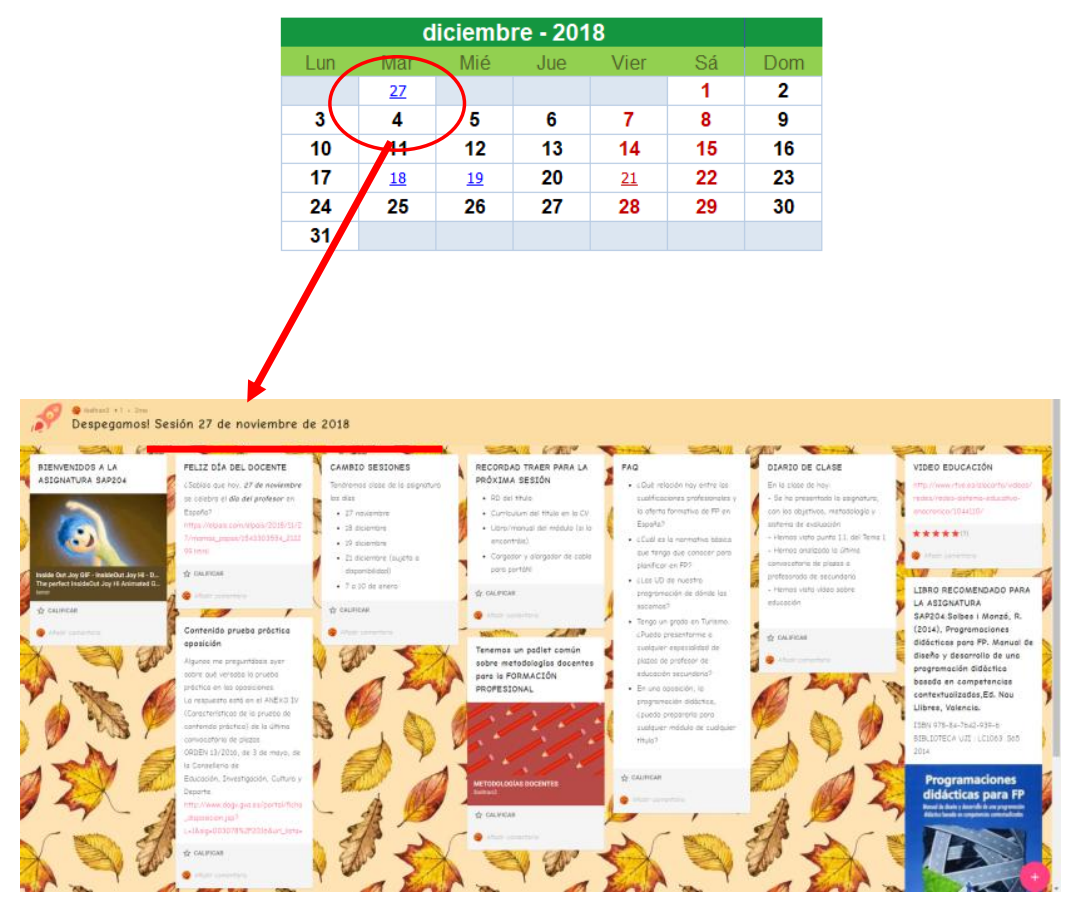

Figure 4. Class resources in Padlet.

\subsection{Class diary}

A class diary is a report created immediately after each session that includes a summary of the session and qualitative data about the teaching process. We proposed our students to work in small groups (5 people maximum). Each group was responsible for the class diary of a session (Figure 5). The benefits of this diary are twofold. On the one hand, it provides the teacher with valuable information about the development of the sessions: how did the students feel? what did they get out of the session? does the teacher need to explain anything again?, etc. On the other hand, it allows students that could not attend the session to check the progresses made in the class. 


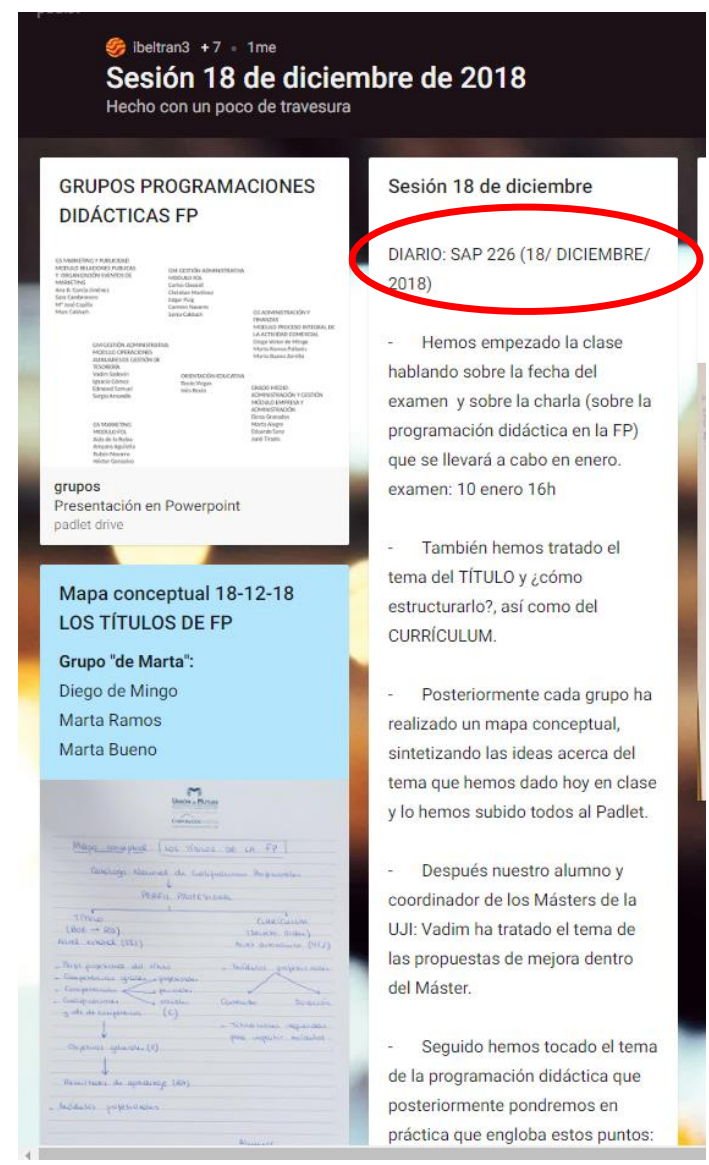

Figure 5. Class diary in Padlet.

\subsection{Frequently asked questions}

We also created a section entitled "FAQ" with the answers to some of the most relevant questions that arose during the session. The teacher was the responsible for this section by including short and clear answers to the students' concerns (e.g. how many questions will the exam have?).

\subsection{Brainstorming}

Padlet is a suitable tool for brainstorming because it provides an easy and quick way to place the students' ideas on the wall. It also allows archiving brainstorming ideas and using them when needed. Padlet allows the student's postings to been viewed simultaneously by other students thus contributing to the generation of new ideas. In our case, we decided that the contributions to the wall were anonymous in order to motivate the students' participation in the task. For example, in our course, we used Padlet to generate ideas about 
the current education system based on a video by Ken Robinson. Students could individually add their thoughts to the wall at the same time other students were contributing with their ideas. We also asked these students to work in small groups to analyze the ideas from everyone in the classroom.

\subsection{Online dialogue}

Padlet also allows to conduct an interactive debate among students. Padlet offers different collaboration options, such as the possibility to insert comments on others' posts or to react with a voting system (Figure 6). These options provide opportunities for online dialogue and even for peer-assessment because students have immediate access to the reactions of their classmates to their contributions in the wall.

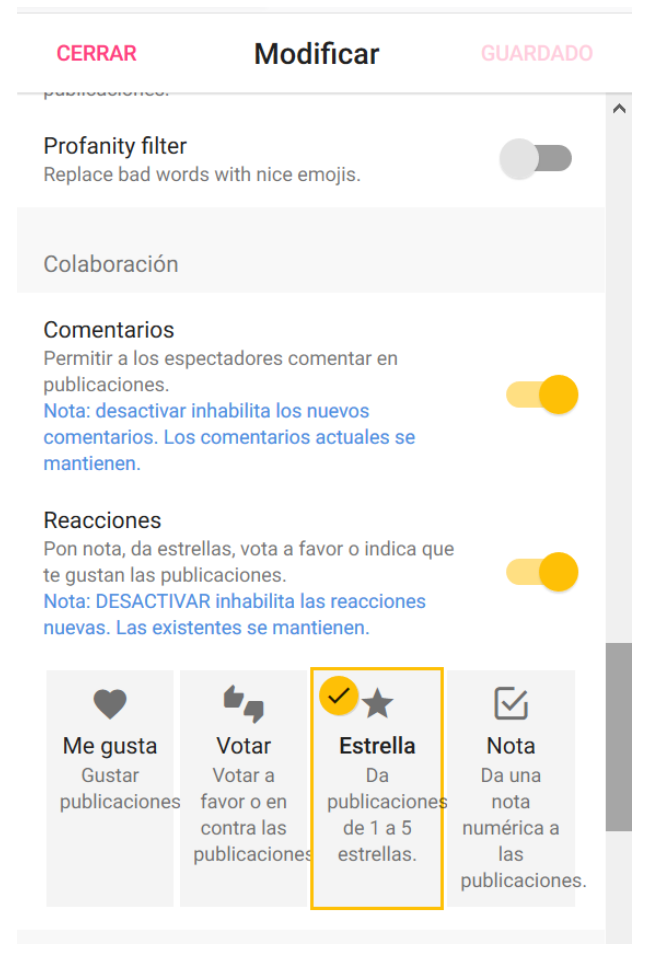

Figure 6. Online dialogue options in Padlet.

\section{Results}

The result of the activities described in the previous section was a digital repository of material and guidelines of the subject. This repository is dynamic, since each year, the content of Padlet may be different and it is cumulative, because students can have access to the content included in Padlets built in the past. As regards students' satisfaction with 
Padlet, we used a survey to assess the students' opinions. In doing so, we used Kleinsmith's (2017) scale, made up of 8 items assessed with a 5-point Likert scale (agreement/disagreement). We distributed this survey through the virtual classroom of the subject using a Google formulary. In general, the results indicate that students are highly satisfied with Padlet, given that all the items obtained values higher than 3 (see Table 1). More specifically, item number 1 attains the highest value, with a mean value of 4,5. Following this, item number 4 has a mean value of 4,2 points. Questions number 2 and 3 also attain mean values close to 4 . In addition, it is remarkable the academic performance of students, with a mean grade of 8,43 (in a 10-point scale). Unfortunately, we could not compare these results with a control group in order to analyze the extent to which Padlet contributes to the academic performance of students.

Table 1. Results of the satisfaction survey.

\begin{tabular}{lcc}
\hline Questions & Mean & s.d. \\
\hline 1. Padlet was easy to use. & 4.50 & 0.70 \\
2. Using padlet helped me to better understand what I was learning in class. & 3.90 & 1.50 \\
3. Padlet allowed me to easily work together with my classmates. & 3.90 & 1.28 \\
4. I felt comfortable sharing my answers on Padlet. & 4.20 & 0.78 \\
5. After using Padlet, I performed higher on my daily assessments. & 3.30 & 1.76 \\
6. After using Padlet, I was more engaged in my learning. & 3.20 & 1.98 \\
7. I enjoyed using Padlet. & 3.40 & 1.50 \\
8. I would like to use Padlet in the future. & 3.60 & 1.57 \\
\hline
\end{tabular}

\section{Discussion}

This work introduces a teaching innovation based on online collaborative learning through Padlet. The result of this experience is a repository of material for the subject. In addition, students felt highly satisfied with the use of this tool in class and reached a good academic performance in the subject. We can summarize the main contributions of our study as follows: First, we believe that information technologies do not substitute but rather, reinforce the interactions among students and between them and the teachers. Padlet supported the collaborative work of the students both in small groups and in big group. This is a very intuitive tool, so students were ready to use Padlet from the very beginning of the subject and we did not have to invest time in initial training. Furthermore, Padlet allowed the teacher to assess continually the evolution of the students' progresses and difficulties, by reviewing real-time contributions of each student and group of students in the wall. In 
addition, Padlet encourages students' reflections about their own learning and increase the flexibility of the learning process, since both students and teachers can contribute to the wall anywhere and anytime. Second and in line with MacDonald's (2003) suggestions, the effective implementation of information technologies in support of collaborative learning should be based on the students' attitudes towards cooperation. They should be aware that collaboration with their classmates will contribute to their own learning. In this sense, the use information technologies in support of collaborative learning needs the modification of the values and philosophy of the class. We believe that the joint assessment between the students and the teacher of these values were very important in this process. From the first day, the teacher emphasized the need to "build together" the subject. In fact, the material of this subject was not available for students in the virtual classroom and they built this material daily through their contributions to Padlet. Third, online collaboration contributed to increase students' competencies beyond those included in the study guide of the subject, such as team abilities, time management skills or negotiation competences and improve some affective outcomes such as team contentiousness or intrinsic motivation.

We believe that our proposal is a first step towards the use of information technologies in collaborative learning contexts. Nonetheless, our study has several limitations. On the one hand, we could not compare the benefits of Padlet in comparison to other digital platforms. In addition, our proposal is based on a sample of Master students so we could not assess the suitability of this tool in different context, for instance in groups of undergraduate students.

\section{References}

Cavanagh, M. (2011). Students' experiences of active engagement through cooperative learning activities in lectures. Active Learning in Higher Education, 12, 23-33.

Fuchs, B. (2014). The writing is on the wall: using Padlet for whole-class engagement. LOEX Quarterly, 40(4), 7-9.

Harasim, L.M., Hiltz, S.R., Teles, L. and Turoff, M. (1995). Learning networks: A field guide to teaching and learning online. Cambridge, MA: MIT Press.

Hsu, Y.C., Ching, Y.C. and Grabowski, B.L. (2014). Web 2.0 applications and practices for learning through collaboration. In J.M. Spector, M.D. Merrill, M.J. Bishop and Elen, J. (Eds.). Handbook of Research on Educational Communications and Technology. New York: Springer Science + Business Media.

Kirschner, P.A. (2001). Using integrated electronic environments for collaborative teaching/learning. Learning and Instruction, 10, 1-9.

Kleinsmith, C. L. (2017). The effects of using Padlet on the academic performance and engagement of students in a fifth grade basic skills mathematics classroom, Rowan University. Rowan Digital Works.

Macdonald, J. (2003). Assessing online collaborative learning: process and product. Computers \& Education, 40: 377-391. 
Resta, P. and Laferrière, T. (2007). Technology in support of collaborative learning. Educational Psychology Review, 19, 65-83.

Weller, A. (2013). Learning in science education. Research in Teacher Education, 3, 40-46.

Zhi, Q., \& Su, M. (2015, October). Enhance Collaborative Learning by Visualizing Process of Knowledge Building with Padlet. In Educational Innovation through Technology (EITT), 2015 International Conference of (pp. 221-225). IEEE. 